\title{
Clinical utility gene card for: Long-QT syndrome
}

\author{
Britt M. Beckmann $\mathbb{1}^{1,2} \cdot$ Stefanie Scheiper-Welling ${ }^{1} \cdot$ Arthur A. M. Wilde ${ }^{3,4,5} \cdot$ Stefan Kääb ${ }^{2,6} \cdot$ Eric Schulze-Bahr $^{4,7}$. \\ Silke Kauferstein ${ }^{1}$
}

Received: 7 December 2020 / Revised: 25 March 2021 / Accepted: 23 April 2021 / Published online: 24 May 2021

(c) The Author(s) 2021. This article is published with open access

\section{Disease characteristic}

\subsection{Name of the disease}

Long-QT syndrome (LQT, LQTS, Romano-Ward syndrome, subgroups: Jervell \& Lange-Nielsen syndrome, Andersen-Tawil syndrome, Timothy syndrome, Ankyrin-B syndrome, Cardiac-only Timothy syndrome, Triadin knockout syndrome).

Comment: It may be appropriate to limit the use of numbered LQTS to LQTS $1-3$ and the remaining to their pathogenic basis, such as CALM-LQTS rather than LQT14 [1].

\subsection{OMIM\# of the disease}

\#192500 (LQT1, KCNQ1-LQTS)

\#613688 (LQT2, KCNH2-LQTS)

\#603830 (LQT3, SCN5A-LQTS)

Britt M. Beckmann

beckmann@med.uni-frankfurt.de

1 Department of Legal Medicine, University Hospital Frankfurt, Frankfurt am Main, Germany

2 Department of Medicine I, University Hospital, LMU Munich, Munich, Germany

3 Amsterdam UMC, University of Amsterdam, Heart Center, Amsterdam, The Netherlands

4 European Reference Network for Rare and Low Prevalence Complex Diseases of the Heart (ERN GUARDHEART; http:// guardheart.ern-net.eu), Amsterdam, The Netherlands

5 Department of Clinical and Experimental Cardiology, Meibergdreef 9, 1105 AZ Amsterdam, The Netherlands

6 German Center for Cardiovascular Research (DZHK), Partnersite Munich, Munich, Germany

7 Institute for Genetics of Heart Diseases, University Hospital Münster, Münster, Germany

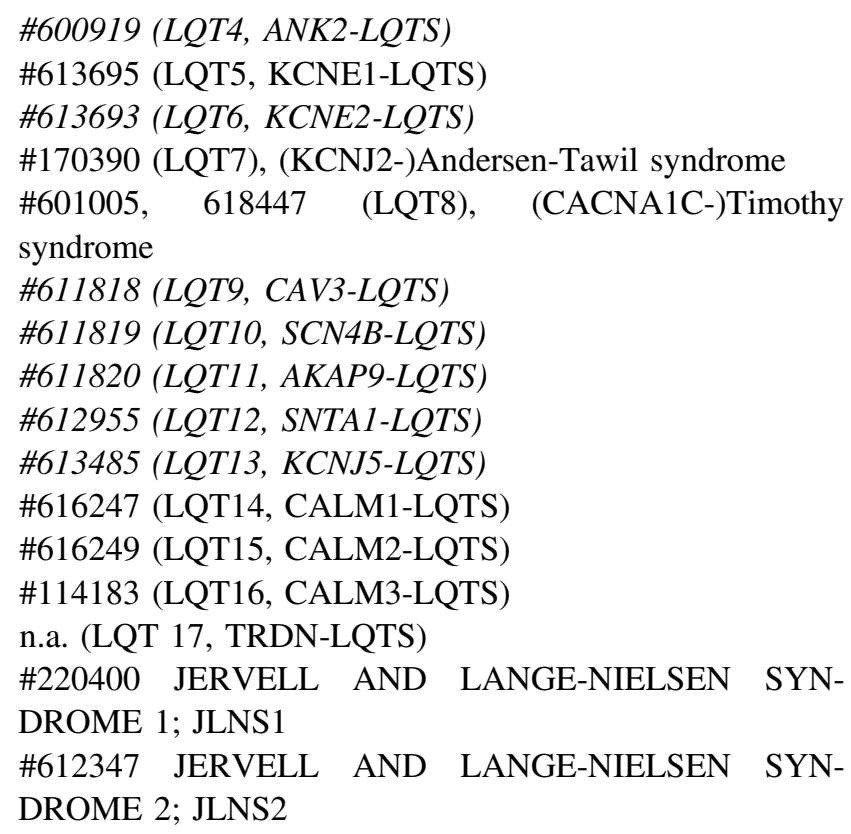

Legend to Table 1.2.: Table 1.2 reflects the previous entries in OMIM. As for several of the entries, there is only disputed evidence for disease causation, those entries that are now regarded as having disputed evidence were presented in italics.

\subsection{Name of the analysed genes or DNA/ chromosome segments and OMIM\# of the gene(s)}

LQT1: KCNQ1, 11p15.5-p.15.4; 607542

LQT2: KCNH2, 7qq36.1; 152427

LQT3: SCN5A, 3p22.2; 600163

LQT4: ANK2, 4q25-q26; 106410

LQT5: KCNE1, 21q22.12; 176261

LQT6: KCNE2, 21q22.11; 603796

LQT7:KCNJ2, 17qq2432; 600681

LQT8: CACNA1C, 12p13.33; 114205

LQT9: CAV3, 3p25.3; 601253

LQT10: SCN4B, 11q23.3; 608256 
LQT11:AKAP9, 7q21.2; 604001

LQT12: SNTA1, 20q11.21; 601017

LQT13: KCNJ5, 11q24.3; 600734

LQT14: CALM1, 14q32.11; 114180

LQT15: CALM2, 2p21; 114182

LQT16: CALM3, 19q13.32; 114183

TRDN-LQTS: 6q22.31; 603283

ATS: KCNJ2, 17qq2432; 600681

JLNS1: KCNQ1, homozygous or compound heterozygous, 11p15.5-11p15.4; 607542

JLNS2: KCNE1, homozygous or compound heterozygous, 21q22.12; 176261

TS: CACNA1C, 12p13.33; 114205

\subsubsection{Core genes (irrespective if being tested by Sanger sequencing or next-generation sequencing) (Table 1)}

Table 1 Core genes [1].

\begin{tabular}{llc}
\hline Gene & Protein & HGNC ID \\
\hline KCNQ1 & $\begin{array}{l}\text { Potassium voltage-gated channel subfamily Q } \\
\text { member 1 }\end{array}$ & 6294 \\
KCNH2 & $\begin{array}{l}\text { Potassium voltage-gated channel subfamily H } \\
\text { member 2 }\end{array}$ & 6251 \\
SCN5A & Sodium voltage-gated channel alpha subunit 5 & 10593 \\
\hline
\end{tabular}

1.3.2 Additional genes with disease gene validity (if tested by next-generation sequencing, including whole exome/ genome sequencing and panel sequencing) (Table 2)

Table 2 Reported genes with disease validity for LQTS [1].

\begin{tabular}{llc}
\hline Gene & Protein & HGNC ID \\
\hline CACNA1C & $\begin{array}{l}\text { Calcium Voltage-gated channel subunit } \\
\text { alpha 1C }\end{array}$ & 1390 \\
CALM1 & Calmodulin-1 & 1442 \\
CALM2 & Calmodulin-2 & 1445 \\
CALM3 & Calmodulin-3 & 1449 \\
KCNE1 & Potassium voltage-gated channel & 6240 \\
& subfamily E regulatory subunit 1 & \\
KCNJ2 & $\begin{array}{l}\text { Potassium voltage-gated channel } \\
\text { subfamily J member 2 }\end{array}$ & 6263 \\
TRDN & Triadin & 12261
\end{tabular}

\subsection{Mutational spectrum}

Out of the 17 genes reported to be associated with LQTS, 3 genes $(K C N Q 1, K C N H 2, S C N 5 A)$ are classified having definitive evidence as a genetic cause for LQTS. In more than
$90 \%$ of the positive LQTS cases a variant affecting function is found in these three core genes. In addition, CALM1, CALM2, $C A L M 3$ and TRDN have a definitive or strong evidence for disease causation, but are associated with specific features. For variants affecting function in the three $C A L M$ genes, LQTS may present during infancy or early childhood with heart block and severe QT prolongation. At least 30\% of patients with clinical clear LQTS are genotype elusive. Common variations likely contribute to phenotype in cases without a known Mendelian variant, but it is likely that there are other genetic and non-genetic factors involved [2].

Cases with TRDN mutations presented during early childhood with QT prolongation, negative $\mathrm{T}$ waves in precordial leads and exercise-induced arrhythmia related to homozygous or compound heterozygous disease-associated variants. Cases with biallelic loss-of-function variants in TRDN can present with either a CPVT or LQTS-like phenotype. Prolonged QTc is not always observed. In cases where it is, it can be classified as atypical LQTS but this is not always the case. The gene CACNAIC was reported to have a moderate evidence for disease causation in the absence of multiorgan involvement as in Timothy syndrome. The level of evidence for the gene KCNJ2 was only limited for the cardio-specific phenotype of LQTS, whereas both genes (CACNAIC and KCNJ2) were classified to have definitive evidence for causing multiorgan syndromes (respectively: Timothy syndrome and Andersen-Tawil syndrome). Timothy syndrome might be associated with distinctive facial features, developmental delay, endocrine abnormalities and congenital heart defects besides bradycardia, QT prolongation and polymorphic arrhythmias [3]. Extracardiac manifestations of Andersen-Tawil syndrome may present as hypo-or hypercalemic episodes of paralysis (periodic paralysis) and morphological characteristics as low set ears, clinodactyly or hypertelorism. Andersen-Tawil syndrome is still classified as LQTS although prominent $U$ waves tempted to determine a prolonged QT interval due to inclusion of the $\mathrm{U}$ wave [4].

Variants affecting function in the genes $A K A P 9, A N K 2$, $C A V 3, K C N E 2, K C N J 5, S C N 4 B$ and SNTAl are classified as having disputed evidence of disease validity and were, therefore, not included in Tables 1-3 [1, 4].

The spectrum of disease-associated variants (of the loss-offunction subtypes) contains practically all types of variants affecting function (missense, nonsense, splice site, deletions and insertions). Most patients are heterozygous for a variant affecting function, but in 5\% of the cases, patients carry two disease-associated variants in the same or different genes.

\subsection{Analytical validation}

Sequencing of all coding exons and intron-exon boundaries of the eligible genes as listed above. Analysis can be performed by Sanger sequencing, (as part of a (cardio) defined gene 
Table 3 Classification of genetic evidence for genes reported to be associated with LQTS based on the work of a multicentered, international clinical domain channelopathy working group $[1,4]$.

\begin{tabular}{lllll}
\hline Gene & LQTS & Acquired LQTS & Multiorgan subtype & Frequency \\
\hline CACNA1C & Moderate & Definitive (Timothy syndrome) & $\sim 1-2 \%[29]$ \\
CALM1 & Definitive $^{\mathrm{a}}$ & & & $\sim 1-2 \%[30]$ \\
CALM2 & Definitive $^{\mathrm{a}}$ & & & $\sim 1 \%[30]$ \\
CALM3 & Definitive $^{\mathrm{a}}$ & & & $<1 \%[31]$ \\
KCNE1 & Limited & Strong & & $<1 \%[32]$ \\
KCNH2 & Definitive & & Definitive (Andersen-Tawil syndrome) & $\sim 25-30 \%[33]$ \\
KCNJ2 & Limited & & & $<1 \%[34]$ \\
KCNQ1 & Definitive & & $\sim 30-35 \%[35]$ \\
SCN5A & Definitive & & $\sim 5-10 \%[36]$ \\
TRDN & Strong & & $\sim 2 \%[37]$ \\
\hline
\end{tabular}

af presenting in infancy or early childhood with heart block and severe QT prolongation.

${ }^{b}$ Presenting with negative $\mathrm{T}$ waves in precordial leads, and exercise-induced arrhythmias in early childhood related to homozygous or compound heterozygous frameshift mutations. panel) targeted next-generation sequencing or by whole exome/genome sequencing. Deletions/duplications can be identified using different methods. For instance, multiplex ligation-dependent probe amplification, quantitative PCR, etc.

Sequencing by the Sanger method is predicted to detect $>99 \%$ of variants in the target regions. Sequencing of both strands (forward and reverse) is recommended. An independent analysis of a second sample of the patient is warranted.

Using NGS as the sequencing method, the sensitivity will depend on the characteristics of test, including (sequencing strategy (e.g. panel/exome/genome), enrichment method), coverage of target regions, base quality and read depth.

Classification of detected variants should be performed according to published standards (e.g. standards of the American College of Medical Genetics and Genomics (ACMG) [5] and should be used with customisation for the specific features of LQTS and its associated genes.

\subsection{Estimated frequency of the disease}

(Incidence at birth ('birth prevalence') or population prevalence. If known to be variable between ethnic groups, please report):

$1: 2,000$ in the general population. It may be assumed that the prevalence is of comparable magnitude in different populations [6].

\subsection{Diagnostic setting}

\begin{tabular}{lll}
\hline & Yes. & No. \\
\hline A. (Differential) diagnostics & $\bigotimes$ & $\square$ \\
B. Predictive Testing & $\square$ & $\square$ \\
C. Risk assessment in Relatives & $\bigotimes$ & $\square$ \\
D. Prenatal & $\bigotimes$ & $\square$ \\
\hline
\end{tabular}

Comments:

Comment 1: Prenatal diagnosis of Long-QT syndrome is indicated in very exceptional situations only and is asked for extremely rarely.

Comment 2: Among clinically definite LQTS cases the three most frequently affected genes with a disease-causing change are KCNQ1, KCNH2 and SCN5A. Most of the LQTS patients are heterozygous for a variant affecting function, but in $\sim 5 \%$ of the cases, patients carry two variants affecting function in the same gene (compound heterozygous or homozygous), or in different genes (digenic) [7, 8]. In general, this is associated with a more severe phenotype with younger age of onset and more adverse events, suggesting a gene-dosage effect.

Comment 3: Copy number variation might be present in $3-12 \%$ of patients in core genes [9-13].

\section{Test characteristics}

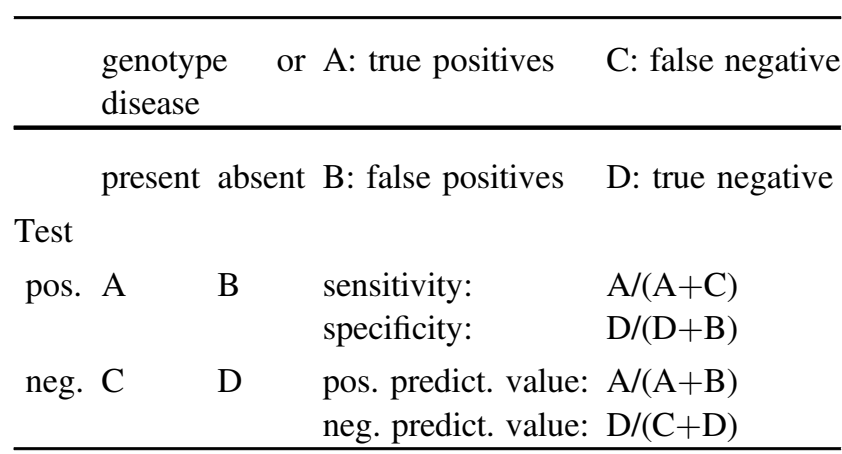

\subsection{Analytical sensitivity}

(proportion of positive tests if the genotype is present in the analyte) 


\subsection{1 if tested by conventional Sanger sequencing}

Close to $100 \%$ if complete Sanger sequencing and deletion/ duplication (MLPA) analysis of the affected clinically important regions of each gene is performed. MLPA is indicated for $K C N Q 1, K C N H 2$ and $K C N J 2$. In $S C N 5 A$ there is insufficient evidence for CNV causing a gain-of-function.

But this nearly $100 \%$ analytical sensitivity includes variants affecting function as well as variants that are just innocent bystanders where the clinical impact has to be proven subsequently. Potential non-coding pathogenic variants in the 3 core genes may remain undetected by standard sequencing approaches, e.g. deep intronic splice variants.

\subsection{2 if tested by Next-generation sequencing}

Analytical sensitivity for single nucleotide variants, insertions and deletions: $>99 \%$ at $\geq 50 \times$ read depth if MLPA and bioinformatic copy number variation (CNV) analysis is included (targeted next-generation sequencing panel approach) [14].

Lack of coverage of specific target regions is a common problem of all NGS platforms. In some cases, the problem can be particularly relevant. For example, some exons of $\mathrm{KCNH} 2$ are frequently not completely covered due to their high CG-rich sequence. Thus, additional analysis by Sanger sequencing of these uncovered regions is often required $[15,16]$. Core genes (KCNQ1, KCNH2, SCN5A) including flanking splice sites should be entirely and sufficiently covered (at least 20x). Potential non-coding pathogenic variants in the 3 main genes may remain undetected by standard sequencing approaches, e.g. deep intronic splice variants.

\subsection{Analytical specificity}

(proportion of negative tests if the genotype is not present)

\subsection{1 if tested by conventional Sanger sequencing}

Close to $100 \%$ if complete sequencing and MLPA of the affected gene is performed. But not finding a diseaseassociated variant rejects by no means the diagnosis LQTS in definite clinical cases as in about 30\% the underlying cause or causative genes are still not known.

\subsection{2 if tested by Next-generation sequencing}

See 2.2.1

\subsection{Clinical sensitivity (proportion of positive tests if the disease is present)}

The clinical sensitivity can be dependent on variable factors such as age or family history. In such cases, a general statement should be given, even if a quantification can only be made case by case.

\subsection{1 if tested by conventional Sanger sequencing}

On average the detection rate of variants affecting function for the most frequent LQTS disease genes (KCNQ1, $K C N H 2$, and SCN5A) is about 60-70\% [17].

\subsection{2 if tested by next-generation sequencing}

Extra sensitivity due to sequencing additional genes by NGS is minimally higher as each additionally tested gene mentioned in table a.1.3.1 and 1.4 increases sensitivity slightly.

\subsection{Clinical specificity (proportion of negative tests if the disease is not present)}

The clinical specificity can be dependent on variable factors such as age or family history. For instance, some patients show an incomplete phenotype, in some individuals the diagnosis is established in adulthood, because of a late onset of symptoms. These cases can likely result in a lower sensitivity. In such cases, a general statement should be given, even if a quantification can only be made case by case.

\subsection{1 if tested by conventional Sanger sequencing}

About $95 \%$, however, the rate of rare variants of uncertain significance (i.e. non-synonymous genetic variation) in Caucasians is about $4-8 \%$ in Non-Caucasian in the LQTS 1-3 genes [18].

\subsubsection{If tested by next-generation sequencing}

See 2.4.1

\subsection{Positive clinical predictive value (life time risk to develop the disease if the test is positive)}

Before the age of 40 years roughly $40 \%$ of (untreated) patients with LQTS1 and LQTS2 become symptomatic. In LQTS3 this is less, but symptoms may be more severe. Phenotypic expression of the disorder is time-dependent and LQTS subjects maintain a high risk for life-threatening cardiac events after age 40 years, which seems to be less high for LQTS1 [19, 20].

\subsection{Negative clinical predictive value (Probability not to develop the disease if the test is negative)}

(Probability not to develop the disease if the test is negative). 
Assume an increased risk based on family history for a non-affected person. Allelic and locus heterogeneity may need to be considered.

Index case in that family had been tested:

If the index case in that family had been tested and a non-equivocal disease-associated variant had been found in the index patient and the non-affected proband is not a carrier of the identified disease- associated variant close to $100 \%$. In those cases the risk remains as small as the prevalence of the disease in the general population.

Index case in that family had not been tested:

If the patient is clinically affected (prolonged QTc with or without syncope) the index patient has a chance of about $60-70 \%$ carrying a variant affecting function. But only in very rare cases there is an indication for performing LQTS genetic testing in a clinically unaffected relative when the index case has not been tested.

This could be imaginable when in an index case there is a strong clinical suspicion of LQTS and there is no DNA available or the index patient refuses genetic testing. Usually, there is no indication for genetic testing in a clinically unaffected family member with unclear genetic status of the index patient if the ECG is normal.

\section{Clinical Utility}

\section{1 (Differential) diagnostics: The tested person is clinically affected (To be answered if in 1.9 "A" was marked)}

\subsubsection{Can a diagnosis be made other than through a genetic test?}

No. (continue with 3.1.4)

Yes. $\square$

$\begin{array}{ll}\text { Clinically } & \square \\ \text { Imaging } & \square \\ \text { Endoscopy } & \square \\ \text { Biochemistry } & \\ \text { Electrophysiology } & \text { ECG recording }\end{array}$

Measurement of the QTc interval on repeated ECG recordings and typical clinical symptoms (with low sensitivity) [21].

\subsubsection{Describe the burden of alternative diagnostic methods to the patient}

ECGs are a non-invasive procedure with no risks and little inconvenience for the patient. But for the reason of low sensitivity and specificity the burden is psychological: uncertainty of proper diagnosis as well as appropriate clinical care: individual therapy, individual recommendations for treatment, life style adaption and individual risk stratification based on specific subtype are not possible in the absence of a genetic substrate.

\subsubsection{How is the cost effectiveness of alternative diagnostic methods to be judged?}

As far as a disease-causing mutation is identified in the index patient, genetic testing can be offered to apparently healthy relatives within the family in order to determine if they carry the same variant affecting function and are at risk for malignant ventricular arrhythmias. If the relative carries the known disease-associated variant a prophylactic inexpensive medical treatment can be started and specific advice can be given to gene carriers (avoiding substances/drugs which might trigger arrhythmias, avoidance of genotype-specific triggers for arrhythmias, careful attendance in case of pregnancy and delivery, reproductive counselling, counselling concerning choice of profession). There is a reduction of the relative risk for developing serious cardiac events of about $65 \%$ by proper treatment (mostly with an inexpensive betablocker therapy) and the cardiac events in untreated patients on the other hand may lead to early invalidity or death in otherwise often healthy young people with putative high economic loss.

3.1.4 Will disease management be influenced by the result of a genetic test?

No.

Yes. \

Therapy (please Pharmaceutical treatment (usually describe) beta-blockers) as primary and secondary prevention. In rare individual cases additional pacemaker and/or an implantable cardioverter defibrillator (ICD), and/ or left cardiac sympathetic 
Table (continued)

$\begin{array}{ll}\text { denervation (LCSD) is used. The } \\ \text { implantation of an ICD with or } \\ \text { without the performance of LCSD } \\ \text { is mostly reserved for patients in } \\ \text { which optimal non-invasive ther- } \\ \text { apy and lifestyle modifications fail } \\ \text { to protect against ventricular } \\ \text { arrhythmias. Only in exceptional } \\ \text { individual cases ICD implantation } \\ \text { might be indicated for primary } \\ \text { prevention. For more specific } \\ \text { therapeutic recommendations } \\ \text { please see [22]. } \\ \text { Pharmacotherapy might differ } \\ \text { between genotypes. Also, life style } \\ \text { advices are different for the dif- } \\ \text { ferent genotypes [23, 24]. } \\ \text { Prognosis (please } & \text { In general, even in asymptomatic } \\ \text { subjects carrying the disease asso- } \\ \text { ciated variant, regular preventive } \\ \text { medical check-ups to recognise } \\ \text { disease progression early, and } \\ \text { appropriate treatment improve } \\ \text { prognosis. On appropriate treat- } \\ \text { ment and with appropriate life } \\ \text { style adjustments prognosis is } \\ \text { good in the vast majority of } \\ \text { patients and may not differ from } \\ \text { normal [25, 26]. } \\ \text { Regular preventive medical con- } \\ \text { sultation of carriers of a variant } \\ \text { affecting function, adjustment or } \\ \text { intensification of therapy if appro- } \\ \text { priate (including defibrillator } \\ \text { implantation and/or LCSD), if } \\ \text { necessary. } \\ \text { The molecular-genetic information } \\ \text { is very important for counselling } \\ \text { and clinical management related to } \\ \text { disease. }\end{array}$

\subsection{Predictive setting: the tested person is clinically unaffected but carries an increased risk based on family history}

(To be answered if in 1.9 "B" was marked)
3.2.1 Will the result of a genetic test influence lifestyle and prevention?

Regular cardiological check-ups.

Life style adjustment, avoiding event related triggers (e.g. swimming in LQTS1 and loud acoustic stimuli in LQT2) [7, 8]. Avoiding stringent competition sports (LQTS1). Avoiding QT prolonging drugs (www. crediblemeds.org; all subtypes) and avoidance of fever (especially in LQTS2) [27, 28].

Some disease associate variants have an unusually high clinical severity (e.g., KCNQ1 A341V) [9]. Also patients with compound heterozygous variants affecting function and JLNS patients are at a higher risk.

If the test result is negative (please describe):

Precautionary measures as described above are not needed.

3.2.2 Which options in view of lifestyle and prevention does a person at-risk have if no genetic test has been done (please describe)?

Same as described above. However, the preventive measures are much better accepted and compliance is improved if a positive test result was obtained.

\subsection{Genetic risk assessment in family members of a diseased person}

(To be answered if in $1.9^{\prime}$ ' $\mathrm{C}$ ' was marked)

3.3.1 Does the result of a genetic test resolve the genetic situation in that family?

If a disease-associated variant is found: yes. Otherwise, potentially affected relatives should undergo regular cardiologic evaluation.

3.3.2 Can a genetic test in the index patient save genetic or other tests in family members?

No. But in case of a positive test result in the index patient, clinically asymptomatic relatives being non-carriers of the disease associate variant can be excluded from regular cardiologic follow-up.

3.3.3 Does a positive genetic test result in the index patient enable a predictive test in a family member?

No. But it enables a diagnostic test in family members with a normal ECG ( $40 \%$ of individuals carrying a variant affecting function). 


\subsection{Prenatal diagnosis}

(To be answered if in 1.9 ' $\mathrm{D}$ ' was marked)

\subsubsection{Does a positive genetic test result in the index patient enable a prenatal diagnosis?}

Yes, but prenatal diagnostics are not actively offered.

\section{If applicable, further consequences of testing}

Please assume that the result of a genetic test has no immediate medical consequences. Is there any evidence that a genetic test is nevertheless useful for the patient or his/her relatives? (Please describe)

For every patient (clinically affected or not) there are known specific triggers for arrhythmias to be avoided (e.g. QT prolonging drugs, competitive sports, low potassium serum levels, swimming in LQTS1, sudden loud noise in LQTS2) $[7,8,23,24]$. Thus, there should be thorough counselling concerning lifestyle modifications and choice of employment.

This work was supported by EuroGentest2 (Unit 2: 'Genetic testing as part of health care'), a Coordination Action under FP7 (Grant Agreement Number 261469) and the European Society of Human Genetics.

Funding Open Access funding enabled and organized by Projekt DEAL.

\section{Compliance with ethical standards}

Conflict of interest The authors declare no competing interest.

Publisher's note Springer Nature remains neutral with regard to jurisdictional claims in published maps and institutional affiliations.

Open Access This article is licensed under a Creative Commons Attribution 4.0 International License, which permits use, sharing, adaptation, distribution and reproduction in any medium or format, as long as you give appropriate credit to the original author(s) and the source, provide a link to the Creative Commons license, and indicate if changes were made. The images or other third party material in this article are included in the article's Creative Commons license, unless indicated otherwise in a credit line to the material. If material is not included in the article's Creative Commons license and your intended use is not permitted by statutory regulation or exceeds the permitted use, you will need to obtain permission directly from the copyright holder. To view a copy of this license, visit http://creativecommons. org/licenses/by/4.0/.

\section{References}

1. Adler A, Novelli V, Amin AS, Abiusi E, Care M, Nannenberg $\mathrm{EA}$, et al. An international, multicentered, evidence-based reappraisal of genes reported to cause congenital long QT syndrome. Circulation. 2020;141:418-28.

2. Lahrouchi N, Tadros R, Crotti L, Mizusawa Y, Postema PG, Beekman L, et al. Transethnic genome-wide association study provides insights in the genetic architecture and heritability of long QT syndrome. Circulation. 2020;142:324-38.

3. Splawski I, Timothy KW, Sharpe LM, Decher N, Kumar P, Bloise $\mathrm{R}$, et al. $\mathrm{Ca}(\mathrm{V}) 1.2$ calcium channel dysfunction causes a multisystem disorder including arrhythmia and autism. Cell. 2004;119:19-31.

4. Giudicessi JR, Wilde AAM, Ackerman MJ. The genetic architecture of long QT syndrome: a critical reappraisal. Trends Cardiovasc Med. 2018;28:453-64.

5. Richards S, Aziz N, Bale S, Bick D, Das S, Gastier-Foster J, et al. Standards and guidelines for the interpretation of sequence variants: a joint consensus recommendation of the American College of Medical Genetics and Genomics and the Association for Molecular Pathology. Genet Med. 2015;17:405-24.

6. Schwartz PJ, Stramba-Badiale M, Crotti L, Pedrazzini M, Besana A, Bosi G, et al. Prevalence of the congenital long-QT syndrome. Circulation. 2009;120:1761-7.

7. Ackerman MJ, Marcou CA, Tester DJ. Personalized medicine: genetic diagnosis for inherited cardiomyopathies/channelopathies. Rev Esp Cardiol (Engl Ed). 2013;66:298-307.

8. Tester DJ, Will ML, Haglund CM, Ackerman MJ Compendium of cardiac channel mutations in 541 consecutive unrelated patients referred for long QT syndrome genetic testing. Heart Rhythm 2005; 2. Available from: URL: https://pubmed.ncbi.nlm.nih.gov/ $15840476 /$

9. Koopmann TT, Alders M, Jongbloed RJ, Guerrero S, Mannens MMAM, Wilde AAM, et al. Long QT syndrome caused by a large duplication in the KCNH2 (HERG) gene undetectable by current polymerase chain reaction-based exon-scanning methodologies. Heart Rhythm. 2006;3:52-5.

10. Barc J, Briec F, Schmitt S, Kyndt F, Le Cunff M, Baron E, et al. Screening for copy number variation in genes associated with the long QT syndrome: clinical relevance. J Am Coll Cardiol. 2011;57:40-7.

11. Tester DJ, Benton AJ, Train L, Deal B, Baudhuin LM, Ackerman MJ. Prevalence and spectrum of large deletions or duplications in the major long QT syndrome-susceptibility genes and implications for long QT syndrome genetic testing. Am J Cardiol. 2010;106:1124-8.

12. Eddy C-A, MacCormick JM, Chung S-K, Crawford JR, Love DR, Rees MI, et al. Identification of large gene deletions and duplications in KCNQ1 and KCNH2 in patients with long QT syndrome. Heart Rhythm. 2008;5:1275-81.

13. Stattin E-L, Boström IM, Winbo A, Cederquist K, Jonasson J, Jonsson B-A, et al. Founder mutations characterise the mutation panorama in 200 Swedish index cases referred for Long QT syndrome genetic testing. BMC Cardiovasc Disord. 2012;12:95.

14. Pua CJ, Bhalshankar J, Miao K, Walsh R, John S, Lim SQ, et al. Development of a comprehensive sequencing assay for inherited cardiac condition genes. J Cardiovasc Transl Res. 2016;9:3-11.

15. Millat G, Chanavat V, Rousson R. Evaluation of a new highthroughput next-generation sequencing method based on a custom AmpliSeq ${ }^{\mathrm{TM}}$ library and ion torrent $\mathrm{PGM}^{\mathrm{TM}}$ sequencing for the rapid detection of genetic variations in long QT syndrome. Mol Diagn Ther. 2014;18:533-9.

16. Novelli V, Gambelli P, Memmi M, Napolitano C. Challenges in molecular diagnostics of channelopathies in the next-generation sequencing era: less is more? Front Cardiovasc Med 2016;3:29.

17. Napolitano C, Priori SG, Schwartz PJ, Bloise R, Ronchetti E, Nastoli J, et al. Genetic testing in the long QT syndrome: development and validation of an efficient approach to genotyping in clinical practice. JAMA. 2005;294:2975-80. 
18. Kapa S, Tester DJ, Salisbury BA, Harris-Kerr C, Pungliya MS, Alders $\mathrm{M}$, et al. Genetic testing for long-QT syndrome: distinguishing pathogenic mutations from benign variants. Circulation. 2009;120:1752-60.

19. Priori SG, Schwartz PJ, Napolitano C, Bloise R, Ronchetti E, Grillo $\mathrm{M}$, et al. Risk stratification in the long-QT syndrome. N Engl J Med. 2003;348:1866-74.

20. Goldenberg I, Moss AJ, Bradley J, Polonsky S, Peterson DR, McNitt S, et al. Long-QT syndrome after age 40. Circulation. 2008;117:2192-201.

21. Hofman N, Wilde AAM, Kääb S, van Langen IM, Tanck MWT, Mannens MMAM, et al. Diagnostic criteria for congenital long QT syndrome in the era of molecular genetics: do we need a scoring system? Eur Heart J. 2007;28:575-80.

22. Priori SG, Blomström-Lundqvist C, Mazzanti A, Blom N, Borggrefe M, Camm J, et al. 2015 ESC Guidelines for the management of patients with ventricular arrhythmias and the prevention of sudden cardiac death: The Task Force for the Management of Patients with Ventricular Arrhythmias and the Prevention of Sudden Cardiac Death of the European Society of Cardiology (ESC). Endorsed by: Association for European Paediatric and Congenital Cardiology (AEPC). Eur Heart J. 2015;36:2793-867.

23. Wilde AAM, Jongbloed RJE, Doevendans PA, Düren DR, Hauer RNW, van Langen IM, et al. Auditory stimuli as a trigger for arrhythmic events differentiate HERG-related (LQTS2) patients from KVLQT1-related patients (LQTS1). J Am Coll Cardiol. 1999;33:327-32.

24. Schwartz PJ, Priori SG, Spazzolini C, Moss AJ, Vincent GM, Napolitano C, et al. Genotype-phenotype correlation in the longQT syndrome: gene-specific triggers for life-threatening arrhythmias. Circulation. 2001;103:89-95.

25. Roth GA, Johnson C, Abajobir A, Abd-Allah F, Abera SF, Abyu $\mathrm{G}$, et al. Global, regional, and national burden of cardiovascular diseases for 10 Causes, 1990 to 2015. J Am Coll Cardiol. 2017;70:1-25.

26. Rohatgi RK, Sugrue A, Bos JM, Cannon BC, Asirvatham SJ, Moir C, et al. Contemporary outcomes in patients with Long QT syndrome. J Am Coll Cardiol. 2017;70:453-62.

27. Amin AS, Herfst LJ, Delisle BP, Klemens CA, Rook MB, Bezzina $\mathrm{CR}$, et al. Fever-induced QTc prolongation and ventricular arrhythmias in individuals with type 2 congenital long QT syndrome. J Clin Invest. 2008;118:2552-61.

28. Burashnikov A, Shimizu W, Antzelevitch C. Fever accentuates transmural dispersion of repolarization and facilitates development of early afterdepolarizations and torsade de pointes under long-QT Conditions. Circ Arrhythm Electrophysiol. 2008;1: 202-8.

29. Boczek NJ, Best JM, Tester DJ, Giudicessi JR, Middha S, Evans $\mathrm{JM}$, et al. Exome sequencing and systems biology converge to identify novel mutations in the L-type calcium channel, CACNA1C, linked to autosomal dominant long QT syndrome. Circ Cardiovasc Genet. 2013;6:279-89.

30. Crotti L, Johnson CN, Graf E, Ferrari GM, de, Cuneo BF, Ovadia $\mathrm{M}$, et al. Calmodulin mutations associated with recurrent cardiac arrest in infants. Circulation. 2013;127:1009-17.

31. Reed GJ, Boczek NJ, Etheridge SP, Ackerman MJ. CALM3 mutation associated with long QT syndrome. Heart Rhythm. 2015;12:419-22.

32. Splawski I, Tristani-Firouzi M, Lehmann MH, Sanguinetti MC, Keating MT. Mutations in the hminK gene cause long QT syndrome and suppress IKs function. Nat Genet. 1997;17:338-40.

33. Curran ME, Splawski I, Timothy KW, Vincen GM, Green ED, Keating MT. A molecular basis for cardiac arrhythmia: HERG mutations cause long QT syndrome. Cell. 1995;80:795-803.

34. Plaster NM, Tawil R, Tristani-Firouzi M, Canún S, Bendahhou S, Tsunoda A, et al. Mutations in Kir2.1 cause the developmental and episodic electrical phenotypes of Andersen's syndrome. Cell. 2001;105:511-9.

35. Wang Q, Curran ME, Splawski I, Burn TC, Millholland JM, VanRaay TJ, et al. Positional cloning of a novel potassium channel gene: KVLQT1 mutations cause cardiac arrhythmias. Nat Genet. 1996;12:17-23.

36. Wang Q, Shen J, Splawski I, Atkinson D, Li Z, Robinson JL, et al. SCN5A mutations associated with an inherited cardiac arrhythmia, long QT syndrome. Cell. 1995;80:805-11.

37. Altmann HM, Tester DJ, Will ML, Middha S, Evans JM, Eckloff $\mathrm{BW}$, et al. Homozygous/compound heterozygous triadin mutations associated with autosomal-recessive long-QT syndrome and pediatric sudden cardiac arrest: elucidation of the triadin knockout syndrome. Circulation. 2015;131:2051-60. 